\title{
PERCEPÇÕES DE LAZER DE PRATICANTES DE MUSCULAÇÃO DE UMA ACADEMIA PRIVADA DE SÃO JOSÉ (SC)
}

Recebido em: 12/04/2016

Aceito em: 10/09/2016

\author{
Elin Eli \\ Universidade do Estado de Santa Catarina (UDESC) \\ Florianópolis - SC - Brasil \\ Priscila Mari dos Santos \\ Universidade Federal de Santa Catarina (UFSC) \\ Florianópolis - SC - Brasil \\ Alcyane Marinho \\ Universidade do Estado de Santa Catarina (UDESC) \\ Florianópolis - SC - Brasil
}

RESUMO: Este estudo teve como objetivo geral investigar as percepções de lazer dos praticantes de musculação de uma academia privada de São José/SC. Foi realizada pesquisa descritiva, com abordagem qualitativa. Participaram 30 pessoas (12 do sexo masculino e 18 do sexo feminino), com média de idade de $36,7 \pm 12,8$ anos, praticantes de musculação há, pelo menos, dois anos. Foi utilizado um roteiro de entrevista semiestruturada. Os dados foram organizados com o auxílio do software NVivo, versão 9.2, e analisados por meio da técnica de análise categorial de conteúdo, modalidade temática. Os resultados indicam que os investigados apresentaram preocupações com o corpo e com a saúde, buscando a musculação principalmente por esses aspectos. Contudo, a maioria percebeu a musculação como lazer, associando-os ao prazer, ao bem-estar, à diversão, ao descanso, à distração, ao tempo disponível e à socialização.

PALAVRAS CHAVE: Percepção. Atividades de Lazer. Treinamento de Resistência.

\section{PERCEPTIONS OF LEISURE OF WEIGHT TRAINING PRACTITIONERS OF A PRIVATE GYM IN SÃO JOSÉ, SC, BRAZIL}

ABSTRACT: This study aimed to investigate the leisure perceptions of weight training practitioners of a private gym in São José, SC, Brazil. A descriptive survey was conducted with a qualitative approach, which included the participation of 30 persons (12 males and 18 females) with a mean age of $36.7 \pm 12.8$ years, weight training practitioners there are at least two years. As data collection instrument we used a semistructured interview guide. Data were organized with the help of NVivo software, version 9.2, and analyzed by categorical analysis technique content in thematic modality. The results indicate that investigated weight training practitioners have concern with body and health, searching mainly for these aspects, the practice of weight 
training. However, most realize the weight as leisure, associating it with pleasure, wellbeing and a moment of socialization.

KEYWORDS: Perception. Leisure Activities. Resistance Training.

\section{Introdução}

A importância do lazer, como objeto de estudo na sociedade contemporânea, agregada à crescente preocupação com a melhoria da qualidade de vida das populações, vem despertando o interesse de estudiosos de variadas áreas do conhecimento (MARINHO et al., 2011). Esse cenário está contribuindo para a valorização do lazer diante da riqueza de possibilidades por ele oferecidas (MARCELLINO, 2012; SILVA et al., 2011).

Nesse contexto, é pertinente ressaltar que o conceito de lazer tem sido discutido por diferentes autores ao longo da história, avançando e contribuindo para a melhor compreensão do fenômeno (GOMES, 2004). Silva et al. (2011) e Marcellino (2012) admitem a importância do lazer como fruto da sociedade contemporânea, considerandoo como um tempo privilegiado para a vivência de valores capazes de contribuir para mudanças de ordem moral e cultural. Gomes (2004) e Marcellino (2012) apontam possibilidades de vivências no lazer a partir de relações dialéticas com as necessidades, os deveres e as obrigações.

Nesta perspectiva, o lazer deveria procurar atender às pessoas no seu todo. Para tanto, é necessário que essas pessoas conheçam os conteúdos que satisfaçam seus vários interesses (MARCELLINO, 2012). A classificação dos conteúdos culturais do lazer proposta por Dumazedier (1980) e complementada por Camargo (1986) distingue seis áreas fundamentais de interesses no lazer: artísticos, manuais, físicos, intelectuais, sociais e turísticos. É importante ressaltar que Dumazedier, em 1980, já destacava o 
caráter pluridimensional dos conteúdos do lazer, enfatizando que um poderia estar contido no outro.

Particularmente sobre os interesses físicos no lazer, Marcellino (2012) exemplifica como vivências que atendem a esses conteúdos: as práticas esportivas, os passeios, a pesca, a ginástica e todas as atividades nas quais prevalece o movimento ou o exercício físico. Neste campo de interesses, as academias são compreendidas como equipamentos específicos de lazer, sejam do ponto de vista da sua organização e funcionamento, ou a partir das percepções dos frequentadores (MARCELLINO, 2003; STUCCHI, 1997).

Stucchi (1997) classificou os equipamentos de lazer quanto à dimensão física do espaço, à população atendida e às finalidades programáticas (conteúdos ofertados). Dessa forma, é possível afirmar que, conforme tal classificação, as academias configuram-se como microequipamentos específicos de lazer, atendendo a uma programação especializada ou a uma faixa de interesses culturais específicos (neste caso, os conteúdos físicos são privilegiados). Geralmente estão localizadas em áreas urbanas, com determinada concentração populacional, funcionando prioritariamente durante os dias da semana.

Por sua vez, para a consideração das academias como espaços de lazer a partir da visão de frequentadores desses locais, é oportuno mencionar o estudo desenvolvido por Marcellino (2003), com 105 frequentadores de 15 academias localizadas em Campinas (SP). O autor constatou que 90\% dos investigados consideram a frequência à academia como uma de suas atividades no lazer.

Para além dos aspectos envolvendo o lazer, é necessário reconhecer que a procura pela prática de exercícios físicos em academias é condicionada por diferentes 
fatores. Nos últimos anos, o aumento da preocupação dos indivíduos com a estética e a saúde, por exemplo, influenciou a expansão das academias pelo país. Segundo dados da International Health, Racquet \& Sportsclub Association (IHRSA), o número de academias no Brasil passou de 7,5 mil em 2006, para 30.767 em 2014. A quantidade de alunos nas academias dobrou no mesmo período, passando de 3,5 milhões de frequentadores em 2006 para sete milhões em 2014 (IHRSA, 2014).

Nesse cenário, a musculação vem se destacando como alternativa de exercício físico que atrai quantidades significativas de pessoas, com os mais variados objetivos. Em muitos casos, a prioridade é a busca imediata por músculos mais fortes e torneados, bem como por emagrecimento. Em outras situações, a procura pela musculação ocorre a partir de recomendação médica, visando ao fortalecimento muscular, à saúde óssea, e ao bem-estar (CUNHA, 2003).

Para além desses objetivos, entretanto, os significados das atividades realizadas em academias, particularmente os significados atribuídos à prática da musculação, parecem transcender questões unicamente estéticas e de saúde, podendo ter relações com a busca pelo convívio social e por redes de amizade, cada vez mais escassos na vida contemporânea (MARCELLINO, 2003). Na visão de Salvador (2008), a socialização pode ser considerada com um fator determinante para a escolha de uma atividade no lazer. Em sua pesquisa sobre os motivos que levam pessoas à prática da musculação, o autor verificou a importância que os praticantes atribuem às amizades estabelecidas na academia e como isso torna o ambiente mais agradável para eles.

A partir dessas considerações, fica claro que o atendimento aos interesses físicos do lazer, concretizado por meio da prática da musculação em academias, parece estar relacionado com interesses sociais, podendo impactar as percepções dos praticantes 
sobre os significados da musculação e também do lazer. Embora seja possível apresentar algumas considerações sobre o lazer na perspectiva de praticantes de musculação, tendo como base estudos envolvendo essa modalidade de exercício físico, em busca realizada no cenário nacional pelas autoras do presente estudo não foram encontradas pesquisas destinadas a investigar as concepções/percepções de lazer considerando exclusivamente praticantes de musculação. Esse cenário retrata uma lacuna científica que, se explorada, poderá contribuir para novas reflexões sobre o lazer, especificamente associado à musculação, podendo repercutir em possibilidades diferenciadas de reflexões e de intervenções na área da Educação Física.

Frente ao exposto, este estudo teve como objetivo geral investigar as percepções de lazer de praticantes de musculação de uma academia privada localizada em São José, Santa Catarina, Brasil. Para tanto, também foram investigados aspectos relativos à prática da musculação, que poderiam contribuir para o entendimento das percepções de lazer dos praticantes. Dessa forma, o estudo que teve como objetivos específicos: identificar os objetivos que impulsionaram os praticantes a buscar a musculação; o tempo de prática de musculação; o tempo diário de permanência na academia; a frequência semanal à musculação; os significados atribuídos à prática da musculação; e as concepções de lazer propriamente ditas desses indivíduos.

\section{Metodologia}

Esta pesquisa, de corte transversal, caracterizou-se como descritiva com abordagem qualitativa dos dados. De acordo com Gaya et al. (2008), a pesquisa descritiva pode demarcar características ou delinear o perfil de determinado grupo ou população, bem como pode contribuir para o esclarecimento de possíveis relações de 
um fenômeno com outras variáveis. Segundo Minayo (2012), a abordagem qualitativa permite conhecer e interpretar a realidade sem nela interferir ou modificar, da mesma forma que trabalhar com o universo de significados, motivos, valores, crenças e atitudes, correspondendo a um espaço mais profundo das relações, dos processos e dos fenômenos.

Participaram voluntariamente desta pesquisa 30 praticantes de musculação (12 do sexo masculino e 18 do sexo feminino) por, pelo menos, dois anos, em uma academia privada localizada na cidade de São José, Santa Catarina, Brasil. Deve-se esclarecer que não foram empregados procedimentos de amostragem probabilísticos para a seleção dos participantes desta pesquisa, tendo sido convidados a participar do estudo todos aqueles que praticavam musculação por, no mínimo, dois anos. Esse tempo de prática foi considerado pelas autoras como o mínimo necessário para a investigação envolvendo percepções relativas à musculação. A academia em questão, por sua vez, foi escolhida por conveniência, considerando a facilidade de acesso pelas pesquisadoras envolvidas.

Os dados desta pesquisa foram obtidos por meio da utilização de um roteiro de entrevista semiestruturada. Conforme Minayo (2012), a entrevista semiestruturada consiste na combinação de perguntas em que o entrevistado tem a possibilidade de falar sobre o tema em questão sem se prender à indagação formulada.

$\mathrm{O}$ roteiro da entrevista desta pesquisa foi composto por perguntas que permitiram explorar os seguintes temas centrais: objetivos que impulsionaram a busca pela musculação; tempo de prática de musculação; tempo diário de permanência na academia; frequência semanal de prática de musculação; significados atribuídos à musculação; e concepções de lazer. Também foram coletadas algumas informações para 
caracterização dos participantes, tais como: sexo, idade, bairro onde mora, estado civil, escolaridade, profissão, ocupação atual, renda mensal aproximada. Para registro das entrevistas foram utilizados gravador de áudio e diário de campo para anotações.

Inicialmente, o responsável pela academia privada localizada em São José (SC), foi contatado para a apresentação da pesquisadora principal e da intenção de realização desta pesquisa. Ao concordar, foi efetuado um levantamento, entre os dados registrados na academia, acerca dos praticantes de musculação neste local há, pelo menos, dois anos. Em posse dessas informações o projeto de pesquisa foi submetido e aprovado pelo Comitê de Ética em Pesquisas com Seres Humanos (CEPSH) da Universidade do Estado de Santa Catarina (UDESC), com parecer n ${ }^{\circ} .732 .824$ de 15/07/2014.

Os indivíduos foram contatados via telefone para a apresentação da pesquisa. Trinta praticantes, com média de idade de $31 \pm 12,8$ anos, aceitaram participar do estudo, sendo convidados a responder ao roteiro de entrevista semiestruturada elaborado especificamente para esta investigação. Para a realização da entrevista foram agendados dias e horários de preferência de cada participante, em um local reservado da academia. Todos assinaram um Termo de Consentimento Livre e Esclarecido (TCLE) em duas vias, sendo uma para a pesquisadora principal e uma para o participante do estudo.

As entrevistas, registradas por meio de um gravador de áudio, foram transcritas na íntegra pela pesquisadora principal e, posteriormente, entregues a cada participante para que alterassem seu conteúdo, como e se julgassem necessário. Este procedimento objetivou validar o conteúdo das entrevistas e aumentar a confiabilidade da investigação. Nenhum participante solicitou alteração/correção na transcrição de sua entrevista. 
Os dados coletados foram organizados no software NVivo, versão 9.2. Este recurso computacional pode ser entendido como uma ferramenta auxiliar para estudos qualitativos, especialmente na área da Educação Física, permitindo o armazenamento de informações e a codificação de dados (MARINHO; SANTOS; FARIAS, 2012).

As informações foram analisadas por meio da técnica de análise categorial de conteúdo, na modalidade temática, seguindo as orientações Bardin (2010). Esta autora descreve a análise de conteúdo como um conjunto de técnicas de análise das comunicações, realizada por meio de procedimentos sistemáticos e objetivos de descrição do conteúdo das mensagens, os quais permitem a obtenção de indicadores para a inferência de conhecimentos relativos às condições de produção/recepção dessas mensagens. A aplicação desta técnica é organizada em três etapas principais: préanálise; exploração do material e tratamentos dos resultados; inferência e interpretação. Os resultados foram apresentados, na seção subsequente, conforme as categorias/temas centrais da investigação. Os nomes dos participantes citados são fíctícios.

\section{Resultados e discussões}

\section{Caracterização dos praticantes de musculação investigados}

Os 30 praticantes de musculação investigados apresentaram média de idade de $36,7 \pm 12,8$ anos, tendo o mais novo 22 anos e o mais velho 68 . Dentre eles, 13 estavam na faixa de 20 a 30 anos; oito, entre 31 e 40 anos; e, nove, acima de 40 anos, indicando uma distribuição equilibrada entre as faixas de idade. As 18 participantes do sexo feminino apresentaram média de idade de 32,3 $\pm 14,4$ anos, enquanto os 12 investigados do sexo masculino apresentaram média de $37,5 \pm 16,8$ anos, revelando uma pequena diferença de idade entre os sexos. Todos residem na Região da Grande Florianópolis 
(SC), onde está localizada a cidade de São José, na qual se encontra a academia em que os indivíduos investigados praticam musculação.

No que se refere ao estado civil, foi possível verificar uma divisão principal entre solteiros(as) ( $\mathrm{n}=14)$ e casados(as) (n=13), mas também houve dois divorciados(as) e uma viúva. Sobre a escolaridade, por sua vez, a maior parte tiveram ensino superior completo $(n=16)$ e nove estavam cursando o ensino superior; quatro cursaram o ensino médio e um o ensino fundamental.

No que concerne à profissão e à ocupação atual (considerando o período de coleta de dados, em 2015), a maioria dos investigados informou trabalhar na sua área de formação acadêmica, destacando-se Educação Física $(n=4)$, Engenharia $(n=3)$, Administração $(n=2)$, Educação $(n=2)$, Direito $(n=1)$, Fonoaudiologia $(n=1)$, Publicidade $(n=1)$ e Design $(n=1)$. Houve também funcionários públicos $(n=3)$, empresários $(n=3)$, estudantes $(n=4)$, aposentados $(n=2)$, técnico em segurança do trabalho $(n=1)$, dona de casa $(n=1)$, representante comercial $(n=1)$, vendedor $(n=1)$ e recepcionista $(\mathrm{n}=1)$. A renda mensal aproximada, por fim, foi de um a dois salários mínimos (considerando o ano de 2015) para quatro participantes; de dois a quatro salários mínimos para oito indivíduos; de quatro a seis salários para seis investigados; e de mais de seis salários mínimos para 12 participantes do estudo.

\section{Objetivos que impulsionaram a busca pela musculação}

Tendo em vista que os participantes do estudo são praticantes de musculação há, pelo menos, dois anos, é pertinente entender os objetivos que impulsionaram a busca por essa prática. Esses dados podem ser visualizados na Tabela 1, a seguir. 
Tabela 1 - Objetivos para a prática de musculação $(n=30)$.

\begin{tabular}{|c|c|}
\hline Objetivos com a musculação & Frequência \\
\hline Hipertrofia muscular & 12 \\
\hline Saúde & 10 \\
\hline Emagrecimento & 6 \\
\hline Condicionamento Físico & 3 \\
\hline Definição muscular & 1 \\
\hline Força muscular & 1 \\
\hline
\end{tabular}

Fonte: autoria própria (2016).

É possível notar que a maioria dos participantes buscou a prática da musculação considerando seus objetivos pessoais de melhoria na saúde e estética corporal. Não foram mencionados, diretamente, objetivos envolvendo a busca pelo lazer por meio da prática de musculação.

Resultados similares a estes foram encontrados no estudo de Marcellino (2003), com frequentadores de academias em Campinas (SP). Neste momento, entretanto, interessa discutir os fins estéticos que impulsionam os participantes a praticar a musculação, referenciados na tabela anterior como hipertrofia, emagrecimento e definição muscular.

Na sociedade atual existe uma preocupação excessiva com o corpo, na qual a estética e a imagem corporal tornaram-se alvo de estudos, como demonstrado por Prazeres (2007). Este autor afirma que as pessoas procuram a musculação como forma de modelagem corporal física, a fím da melhoria da autoimagem. Além disso, as pessoas insatisfeitas com a sua imagem corporal apresentam mais dificuldades de relação interpessoal quando comparadas àquelas plenamente satisfeitas com seus corpos, implicando dificuldades de socialização e tendência ao isolamento.

Assim, a estética corporal parece ser um dos objetivos principais da procura por academias, como também demonstrado por Saba (2001). Tessmer et al. (2006) 
investigaram 315 indivíduos em 13 academias de ginástica da cidade de Pelotas (RS), constatando que quase metade dos participantes estavam insatisfeitos com sua imagem corporal, com maiores riscos de insatisfação com o próprio corpo para pessoas do sexo feminino, obesas e com menos de 19 anos de idade.

Os padrões estéticos que a sociedade impõe, frequentemente por meio da mídia, estabelecem a necessidade da manutenção da forma física a qualquer custo, influenciando a busca das pessoas por realizar atividades físicas em academias (SABA, 2001). Nesse sentido, Tahara e Carnicelli Filho ressaltam a importância do papel do Profissional de Educação Física, no sentido de evidenciar sua função educativa para a adoção de hábitos saudáveis pelas pessoas que optam pela prática de exercícios físicos em seus momentos de lazer, destacando os benefícios para a saúde e não apenas para as questões envolvendo a estética corporal.

O interesse pela prática de exercícios para beneficiar a saúde de forma geral e o condicionamento físico, todavia, também foi vislumbrado pelos participantes deste estudo. A fala de uma participante ilustra bem este resultado:

Saúde, eu busquei a academia pela saúde, depois acabei gostando (Julia, 23 anos).

A prática de exercícios tem sido frequentemente apontada como um dos principais fatores de boa saúde, conforme destacam Matsuo; Miranda e Velardi (2011). Para essas autoras, os projetos embasados na perspectiva de promoção de saúde estão relacionados com a prevenção de doenças. Prazeres (2007) e Matsuo; Miranda e Velardi (2011) enfatizam que populações fisicamente ativas têm menor incidência de doenças e situações patogênicas variadas. 
Dessa forma, são diversos os estudos que reconhecem a importância da musculação para a manutenção da saúde, a melhora da qualidade de vida, da sensação de bem-estar, da estética, entre vários outros aspectos em diferentes faixas etárias (ALMEIDA; SILVA, 2014; SIMÕES et al., 2011; TAHARA; CARNICELLI FILHO, 2009). No presente estudo, a musculação foi percebida como benéfica à saúde, e associada ao envelhecimento, conforme declara um participante do estudo com mais de 60 anos de idade:

[...] além de ser algo que faz bem à saúde (eu sou aposentado), é um modo de você passar o tempo de seu dia. Estar na academia é muito bom [...] (José, 68 anos).

Uma vez reconhecida a analogia entre envelhecimento e doenças, a relação entre saúde e prática de exercícios físicos tem estado presente em programas destinados a idosos. Este assunto merece ser refletido, visto que um participante deste estudo têm mais de 60 anos e oito têm entre 40 e 60, aproximando-se do início da velhice. Zaitune et al. (2007) verificaram que a musculação é difundida entre os idosos pelos benefícios na prevenção na perda de massa óssea, bem como no controle e tratamento da osteoporose. Sobre este assunto, dois participantes demonstram essas preocupações quando questionados sobre os objetivos que o impulsionaram à prática da musculação:

Ganhar massa muscular por causa da idade (Paula, 59 anos).

Eu faço mais por questão de saúde, fortalecer a musculatura, proteção dos ossos, manter o corpo em dia (Rosa, 52 anos).

Fortalecimento da musculatura, desenvolvimento da musculatura, principalmente para minha idade é muito interessante, ter uma vida mais saudável, mais longa se for possível através do trabalho físico (Felipe, 60 anos). 
Frente ao exposto, os resultados apresentados nesta seção contribuem para confirmar que o momento histórico atual é de significativa preocupação com o corpo, com a saúde e com a qualidade de vida. Embora possam existir outros distintos objetivos que impulsionam a busca pela prática da musculação, podendo se constituir, ou não, como possibilidade de lazer, esses dados são importantes para que as percepções de lazer dos investigados sejam consideradas de forma global, aliadas ao exercício físico que praticam.

\section{Tempo diário de permanência na academia, tempo de prática de musculação e}

\section{frequência semanal}

Os entrevistados apresentaram tempo mínimo de dois anos de matrícula na academia em questão e máximo de seis anos. Permanecem aproximadamente uma hora e 30 minutos praticando musculação na academia. Contatou-se que dos 30 entrevistados nesta pesquisa, 18 praticam musculação de seis a mais de 10 anos; os outros 12 de dois a cinco anos, considerando a prática da modalidade em outras academias. Saba (2001) afirma que o envolvimento do praticante com exercícios físicos e esportes em seu histórico pessoal facilita a manutenção da prática, uma vez que as pessoas mais ativas na atualidade muito provavelmente foram ativas no passado.

Com relação à frequência semanal à academia para praticar musculação, a maioria $(n=17)$ informou frequentá-la cinco vezes; alguns frequentam quatro $(n=6)$ ou três $(n=6)$ vezes por semana. Apenas um participante frequenta a academia somente uma vez na semana.

Os aspectos relacionados ao tempo de prática e à frequência semanal parecem estar associados às afirmações dos investigados no sentido de estarem satisfeitos em 
relação às seguintes características da academia: ao ambiente, aos horários, à localização, aos professores, às aulas de ginástica e às instalações da academia, facilitando a aderência ao local, especialmente por meio da prática de musculação. $\mathrm{Na}$ pesquisa de Marcellino (2003), os frequentadores das academias investigadas pelo autor destacaram, em seus discursos, que os aspectos relativos ao espaço físico e aos equipamentos da academia são determinantes para a satisfação. É importante mencionar, também, o fator comodidade, como um dos condicionantes para a escolha e permanência em determinado espaço de lazer, tal qual pode ser considerado a academia. Ademais, para Saba (2001) há um importante elo emocional entre uma pessoa e a atividade a que se propõe, estabelecendo-se um círculo virtuoso de prática, satisfação e resultado, que garante a continuidade da atividade, de forma cada vez mais positiva, em uma crescente evolução rumo aos objetivos pretendidos. Desse modo, a sensação de satisfação originada pelos ganhos no bem-estar físico e psicológico também é essencial para a aderência à prática do exercício.

A prática da musculação por vários anos e, especialmente, na mesma academia, parece estar relacionada ao convívio social estabelecido entre os praticantes, emergindo também das falas aspectos caracterizadores do lazer nesses espaços:

Porque eu tenho contato, converso com os professores, é uma diversão, pra mim é lazer também (Carla, 27 anos).

A academia é muito bom, você conhece pessoas com outros objetivos, faz muita amizade (José, 68 anos).

Nesta perspectiva, observa-se que a interação social é um fator determinante para a aderência e a manutenção da prática da musculação pelos investigados. Essa relação do conteúdo social com os exercícios físicos praticados em academia também foi verificada nos estudos de Cunha (2003) e Marcellino (2003). Dessa forma, as 
academias passam a ser, também, um espaço de convivência e de usufruto do conteúdo social do lazer, para além dos conteúdos físicos, embora, na maioria das vezes, não instituídas com a finalidade de atender aos interesses sociais.

Tahara e Carnicelli Filho (2009) apontam que as pessoas sentem mais prazer e atração pela atividade proposta quando membros do grupo se identificam e se autoconhecem. Segundo os autores, os indivíduos se encontram no mesmo recinto e gestam novas oportunidades de compartilharem sentimentos, emoções e agregarem valor às suas relações. Estes dados estão em sintonia com as ideias de Cunha (2003), especialmente quando a autora afirma que as pessoas não vão a academias apenas para se exercitarem, visto que há uma interação social por trás desse cenário, configurandose como uma possibilidade de convívio que estimula as pessoas a aderirem ao exercício físico nesses espaços.

\section{Significados atribuídos à prática de musculação}

Quando os indivíduos aqui investigados foram questionados acerca dos significados da musculação em suas vidas foi possível observar uma correspondência com os objetivos que os impulsionaram a buscar a musculação. Nessa perspectiva, observou-se que a manutenção da saúde, a procura pela sensação de bem-estar e por melhor percepção de qualidade de vida foram os significados mais frequentemente atribuídos pelos participantes deste estudo à prática da musculação. Os depoimentos a seguir ilustram esses resultados:

É saúde, bem-estar físico, pra mim é tudo, bem-estar físico e mental (Lívia, 23 anos).

[...] Qualidade de vida e me manter saudável para ter uma velhice saudável, porque eu já estou com 47 anos e eu penso muito nisso (Maria, 47 anos). 
Musculação pra mim é ter uma musculatura em dia, proteção dos ossos, um corpo sarado, é um exercício altamente benéfico, principalmente para determinada idade (Joana, 56 anos).

Dessa forma, quando indagados sobre objetivos e significados relativos à prática da musculação os aspectos relacionados à saúde mostraram-se bastante evidentes nos discursos dos investigados, reiterando as discussões anteriormente elencadas acerca da atual preocupação com o corpo e com a qualidade de vida (MATSUO; MIRANDA; VELARDI, 2011; PRAZERES, 2007; SABA, 2001). Por outro lado, quando questionados mais especificamente sobre seu entendimento de lazer, conforme apresentado a seguir, a musculação emergiu como alternativa de vivência nesse âmbito, parecendo transcender os significados e objetivos relativos exclusivamente aos cuidados com o corpo.

\section{Concepções de lazer}

As concepções de lazer dos participantes do estudo foram organizadas conforme os núcleos de sentido de suas falas, quando questionados sobre o que entendem por lazer. A Tabela 2, a seguir, apresenta tais concepções.

Tabela 2 - Concepções de lazer dos participantes do estudo $(\mathrm{n}=30)$.

\begin{tabular}{|c|c|}
\hline Concepções de lazer & Frequência \\
\hline Cuidar do corpo & 14 \\
\hline Tempo livre fora o ambiente de trabalho & 5 \\
\hline Divertir-se & 5 \\
\hline Sentir-se bem & 5 \\
\hline Fazer o que gera prazer & 5 \\
\hline Distrair-se & 3 \\
\hline Estar com a família & 3 \\
\hline Descansar & 3 \\
\hline
\end{tabular}

Fonte: autoria própria (2016). 
É possível observar que os participantes apresentaram diferentes pontos de vista ao responder o que é o lazer. Contudo, a resposta mais frequentemente associada ao fenômeno apresenta-se como "cuidar do corpo". Deve-se ressaltar que os cuidados com o corpo e a busca por um físico "ideal" são discussões constantes na história da humanidade e estão diretamente relacionadas à prática de exercícios físicos (PRAZERES, 2007). No estudo de Torri, Bassani e Vaz (2007), a respeito de uma possível pedagogia dos corpos nas academias, os autores notaram que as preocupações com a saúde e com a beleza alcançaram grande importância na contemporaneidade, estando relacionada ao consumo, cada vez maior, de espaços destinados à prática de atividades corporais vinculadas a certo culto ao corpo. A busca pelo embelezamento e pelo aperfeiçoamento corporal enfrenta sacrifícios e privações por parte dos frequentadores de academia que procuram um ideal de masculinidade e feminilidade. Para os autores supracitados este espaço forja uma pedagogia do corpo, como ele deve, mas, sobretudo, como não deve ser.

Nessa direção, no presente estudo, ao tentarem expor seu entendimento de lazer, alguns participantes enfatizaram essas preocupações com os cuidados envolvendo o corpo:

Cuidar do meu corpo é lazer, porque eu gosto do que eu faço, não faço por obrigação, faço porque eu gosto, gosto de cuidar do meu corpo (Carlos, 35 anos).

Lazer pra mim é vir para a academia. No momento é o meu único lazer, é vir à academia, porque me dá prazer, me faz sentir bem, vai à frente do espelho e vê que teu corpo está mudando para melhor e porque eu me sinto bem na academia fazendo a musculação (Rosa, 52 anos).

Além dos cuidados com o corpo, os depoimentos exemplificados vão ao encontro de duas características do lazer defendidas por Dumazedier (1980): o caráter 
liberatório, significando que o lazer resulta de livre escolha do indivíduo, não sendo resultado de imposição/obrigação; e o caráter hedonístico, marcando a busca de um estado de satisfação (prazer, bem-estar...), representando a condição primária do lazer. Embora o primeiro aspecto seja frequentemente questionado por estudiosos contemporâneos do lazer, no sentido de que sempre haverá obrigações nas diferentes esferas da vida cotidiana (GOMES, 2004; MARCELLINO, 2012), a busca pelo prazer e pelo bem-estar ainda se faz presente nas discussões sobre o lazer como fenômeno social. Também no que se refere às concepções de lazer, percebe-se que os participantes diferenciaram os momentos de trabalho dos momentos de lazer, visto que associaram o "tempo livre" fora do trabalho aos significados de lazer. Isto pode ser exemplificado pela fala de Daniel:

Lazer é um momento que eu tiro um tempo livre pra me divertir, que eu estou longe do meu trabalho, pensando em coisas fora, extra trabalho (Daniel, 44 anos).

A rejeição do trabalho como instante de lazer é algo típico das sociedades urbano-capitalistas. O caráter parcial e restrito com que se vê a questão do lazer é uma grande problemática, afirma Marcellino (2007). O autor explica que há uma produção cultural profissional, que é trabalho, e uma produção "amadora", que é assistência, informação, e se caracteriza como lazer. Andrade; Wiik e Vasconcellos (2004) contribuem com essa discussão ao argumentarem que a sociedade capitalista separou o homem da sua capacidade criadora, fazendo com que o "tempo do trabalho" seja diferente do "tempo do não-trabalho", deixando o lazer vinculado ao último e, portanto, reduzido.

Nesta direção, Marcellino (2007) questiona a parcialidade entre trabalho e lazer, como se fossem dois compartimentos estanques. Para este autor, a alienação em um dos 
campos gera atitudes de evasão e compensação no outro, não possibilitando, assim, o entendimento do lazer, como fenômeno social, na sua totalidade. Segundo Belloni (2001), essa é uma das evidências mais importantes de que as sociedades contemporâneas não podem ser caracterizadas como civilização de lazer, pois associam somente o tempo liberado do trabalho para a satisfação de necessidades pessoais.

Por outro lado, é preciso esclarecer que o lazer nem sempre está associado unicamente às necessidades pessoais. Para Marcellino (2007), pode-se verificar, com maior frequência, que essa associação com necessidades individuais implica visões parciais do lazer, não o considerando na sua totalidade das relações sociais. Essa tendência restritiva, que pode ser constatada na linguagem popular, é frequentemente alimentada pelos meios de comunicação de massas. Os valores mais comumente relacionados ao lazer são o descanso e o divertimento, sendo deixados de lado, principalmente, os valores relativos ao desenvolvimento social, os quais também podem ser propiciados pelo lazer. Esses apontamentos de Marcellino (2007) encontram correspondência com os resultados do presente estudo, visto que a diversão, o descanso e as sensações de prazer e de bem-estar foram aspectos frequentes nas repostas dos participantes, definidores de suas concepções de lazer.

Dentre as demais constatações desta pesquisa, é pertinente destacar que significativo número de pessoas entrevistadas $(n=26)$ percebe a musculação como lazer. A modalidade é associada a este fenômeno social quando propicia aos praticantes o relaxamento (diminuição das tensões do trabalho e do estresse diário), bem-estar, prazer e socialização. Alguns relatos dos participantes do estudo evidenciam esses resultados:

Pelo modo que a gente se dispõe, porque no lazer a gente se sente bem, na musculação a gente também se sente bem, porque a gente tem ganhos como no lazer, ganhos com a amizade, ganhos com modo de conversar ou se expressar, e na academia também a gente vê 
resultados porque a gente se expressa bem com o corpo, acho que esse é o objetivo (João, 30 anos).

É, ajuda a extravasar, eu estou aqui dentro e não consigo pensar em outra coisa, no trabalho, problemas familiares... Eu acho que uma das coisas que caracteriza o lazer é isso, estar naquele momento e estar relaxada não pensando em outras coisas (Ana, 33 anos).

Diante desses resultados, é possível observar, nas percepções dos participantes, uma visão funcionalista do lazer, manifestada no ambiente da academia investigada e associada à prática da musculação. Percebe-se que tal associação tende a compensar a insatisfação e a alienação do trabalho. Nesta perspectiva, o lazer, limitado à função de recuperação e força para o trabalho, tem sua importância reduzida em detrimento de suas possibilidades privilegiadas para a vivência de valores que contribuíssem para mudanças de ordem moral e cultural, conforme explica Marcellino (2012). Em contrapartida, fica evidente a possibilidade de interações sociais proporcionada pela prática de musculação na academia, como vivência no lazer, podendo redimensionar o contexto de relações sociais da vida dos praticantes.

Comprovados os benefícios do exercício físico para a saúde e sua configuração como possibilidade de lazer, ainda assim, alguns praticantes de musculação aqui investigados $(n=4)$ não perceberam a musculação como forma de lazer. Estes participantes informaram que aderiram à modalidade apenas por obrigação, na tentativa de solucionar problemas de saúde, afirmando que a musculação é algo "muito focado", "repetitivo" e "pouco atrativo". O depoimento de um desses investigados evidencia tal percepção:

Não acho que a musculação seja uma possibilidade de lazer porque é uma coisa muito focada, chega no final daqueles três meses, aquele treino já virou uma rotina. Você começa a ficar cansada daqueles exercícios, falta incentivo para vir. Não faço musculação por lazer, é condicionamento físico, é proteção para os meus ossos, manter bumbum e perna tudo certinho, mas lazer não (Joana, 55 anos). 
No estudo de Marcellino (2003), 10\% dos frequentadores de academias entrevistados pelo autor também informaram praticar exercícios por obrigação, considerando principalmente as necessidades de melhoria da saúde e do condicionamento físico. Nota-se que a obrigação é uma constante na vida das pessoas. Os momentos de descanso e de lazer estão ficando cada vez mais escassos e sendo substituídos por obrigações sociais. Trabalhar, ganhar dinheiro, manter a família, educar os filhos e ainda ter o tempo destinado ao lazer gera pressão. Marcellino (2007) afirma que a obtenção de tempo e sua distribuição, não só quantitativa, mas qualitativa, entre as classes sociais, é um fato político: está em jogo uma série de interesses que visam ao controle do tempo e ao seu aproveitamento na produção. Afinal, "tempo é dinheiro", e no sistema de produção vigente dinheiro é poder.

A fim de amenizar essa carga de obrigatoriedade que a sociedade impõe para que as pessoas tenham momentos de lazer cheios de atividades, o autor supracitado sugere a incorporação gradativa dos valores do lazer no campo das obrigações. É preciso que o lazer, além de suas características de descanso, evasão e divertimento, atenda também às necessidades de desenvolvimento pessoal e social das pessoas.

\section{Considerações Finais}

Os praticantes de musculação ora investigados apresentaram preocupação com o corpo e com a saúde, buscando, principalmente por esses aspectos, a prática da musculação. Embora os objetivos com a prática sejam eminentemente estéticos e/ou associados à saúde e à qualidade de vida, reiterando a literatura existente sobre o assunto, a maioria dos participantes do estudo percebeu a musculação como possibilidade de lazer. O fenômeno, como um todo, mas principalmente atrelado à 
musculação, foi percebido como alternativa de diversão, distração, fuga das obrigações cotidianas e possibilidade de socialização. Apesar de esse entendimento de lazer reforçar o pensamento que o senso comum tem sobre o fenômeno, parece que as interações sociais possibilitadas por meio da prática da musculação em academias está sendo determinante não só para a frequência à academia investigada por, no mínimo, dois anos, e na maioria dos dias da semana, como também para conferir relevância ao lazer como esfera da vida capaz de redimensionar outras, neste caso, especificamente relacionada à esfera social.

É pertinente ressaltar que este estudo limitou-se a investigar a realidade de uma academia específica. Porém, as discussões levantadas podem ser abordadas em outros espaços similares, com o intuito de problematizar um assunto que se apresenta emblemático na sociedade atual, a qual privilegia determinados valores em detrimento de outros, tais como aqueles relacionados à estética, por exemplo. Além disso, as reflexões efetuadas podem auxiliar os Profissionais de Educação Física em sua atuação envolvendo a musculação, especialmente no sentido de perceber e de considerar em suas intervenções os diferentes aspectos relativos à prática dessa modalidade, tal como sua percepção como forma de lazer por alguns praticantes e os valores associados a tal fenômeno.

\section{REFERÊNCIAS}

ALMEIDA, Rogério Tosta de; SILVA, Renê Rogério Souza da. Estudo comparativo da autonomia funcional de idosas praticantes de hidroginástica, musculação e não praticantes de exercícios físicos. Revista Brasileira de Ciência e Movimento, Brasília, v. 22, n. 4 , p. 88-96, 2014.

ANDRADE, Cleide Lugarini; WIIK, Cristiano Braune; VASCONCELLOS, Maria da Penha Costa. Corpo e cultura e corpo e saúde: análise do suplemento semanal de um jornal paulista. Saúde e Sociedade, São Paulo, v. 13, n. 3, p. 58-67, set./dez. 2004.

BARDIN, Laureance. Análise de conteúdo. Ed. rev. e atual. Lisboa: Edições 70, 2010. 
BELLONI, Maria Luiza. O lazer espetacularizado: cultura do narcisismo e indústria cultural. Motrivivência, Florianópolis, v. 12, n. 17, p. 1-13, jul. 2001.

CAMARGO, Luiz Octávio de Lima. O que é lazer? São Paulo: Brasiliense, 1986.

CUNHA, Angela Cristina. Os conteúdos físico-esportivos no lazer em academias: atividade ou passividade? In: MARCELLINO, Nelson Carvalho (Org.). Lúdico, educação e educação física. 2. ed. Ijuí: Unijuí, 2003. p. 149-159.

DUMAZEDIER, Joffre. Valores e conteúdos culturais do Lazer. São Paulo: SESC, 1980.

GAYA, Adroaldo et al. Ciências do movimento humano: introdução à metodologia da pesquisa. Porto Alegre: Artmed, 2008.

GOMES, Christianne Luce. Dicionário crítico do lazer. Belo Horizonte: Autêntica, 2004.

IHRSA - INTERNATIONAL HEALTH, RACQUET \& SPORTSCLUB ASSOCIATION (IHRSA Global Report). The state of the health club industry. 2014. Disponível em <https://www.ihrsa.org/ihrsa-global-report $>$. Acesso em: 21 out. 2015.

MARCELLINO, Nelson Carvalho. Academias de ginástica como opção de lazer. Revista Brasileira de Ciência e Movimento, Brasília, v. 11, n. 2, p. 49-54, jun. 2003.

2012.

Estudos do lazer: uma introdução. 5. ed. Campinas: Autores Associados,

. Lazer e cultura. São Paulo: Alínea, 2007.

MARINHO, Alcyane et al. Grupos de Pesquisa em Lazer e Intercâmbios Internacionais. Licere, Belo Horizonte, v. 14, n. 3, p. 1-21, set. 2011.

; SANTOS, Priscila Mari dos; FARIAS, Gelcemar Oliveira. Competências e formação profissional: reflexões sobre um projeto de ensino. Revista Brasileira de Ciência e Movimento, Brasília, v. 20, n. 3, p. 46-54, 2012.

MATSUO, Renata Frazão; MIRANDA, Maria Luiza de Jesus; VELARDI, Marília. O sentido de saúde e as implicações para a prática de educação física em idosos. Revista da Educação Física/UEM, Maringá, v. 22, n. 1, p. 129-138, jan./mar. 2011.

MINAYO, Maria Cecília de Souza. Trabalho de campo: contexto de observação, interação e descoberta. In: ed. Petrópolis: Vozes, 2012. p. 61-77.

PRAZERES, Marcelo Viale. A prática da musculação e seus benefícios para a qualidade de vida. 2007. 46f. Trabalho de Conclusão de Curso (Bacharelado em Educação Física) - Centro de Educação Física, Fisioterapia e Desportos, Universidade do Estado de Santa Catarina, Florianópolis, 2007.

SABA, Fabio. Aderência: à prática do exercício físico em academias. São Paulo: Manole, 2001. 
SALVADOR, Bruno Sales. Motivos de praticantes de musculação em academias. 2008. 43f. Trabalho de Conclusão de Curso (Bacharelado em Educação Física) Faculdade de Educação Física, Universidade Estadual de Campinas, Campinas, 2008.

SILVA, Débora Alice Machado et al. A importância da recreação e do lazer. Brasília: Gráfica e Editora Ideal, 2011.

SIMÕES, Christiane Salum Machado et al. Análise da qualidade de vida de professores e alunos de musculação: um estudo comparativo. Revista Brasileira de Atividade Física \& Saúde, Pelotas, v. 16, n. 2, p. 107-112, 2011.

STUCCHI, Sérgio. Espaços e equipamentos de recreação e lazer. In: BRUHNS, Heloisa Turini (Org.). Introdução aos estudos do lazer. Campinas: Unicamp, 1997. p. 105121.

TAHARA, Alexander Klein; CARNICELLI FILHO, Sandro. Atividades físicas de aventura na natureza (AFAN) e academias de ginásticas: motivos de aderência e benefícios advindos da prática. Movimento, Porto Alegre, v. 15, n. 3, p. 187-208, jul./set. 2009.

TESSMER, Chiara Scaglioni et al. Insatisfação corporal em frequentadores de academia. Revista Brasileira de Ciência e Movimento, Brasília, v. 14, n. 1, p. 7-12, 2006.

TORRI, Gisele; BASSANI, Jaison José; VAZ, Alexandre Fernandez. Dor e tecnificação no contemporâneo culto ao corpo. Pensar a Prática, Goiânia, v. 10, n. 2, p. 261-273, jul./dez. 2007.

ZAITUNE, Maria Paula do Amaral et al. Fatores associados ao sedentarismo no lazer em idosos, Campinas, São Paulo, Brasil. Caderno Saúde Pública, Rio de Janeiro, v. 23, n. 6, p. 1329-1338, jun. 2007.

\section{Endereço das Autoras:}

Elin Eli

Avenida salvador Di Bernardi, 888.Campinas

São José - SC - 88.101260

Endereço Eletrônico: elin.eli@hotmail.com

Priscila Mari dos Santos

Servidão Dona Vitorina Lopes, s/n. - Campeche

Florianópolis - SC - 88.066026

Endereço Eletrônico: priscilamarisantos@hotmail.com

Alcyane Marinho

Rua Vereador Ramon Filomen, 357, apto. 1001

torre 1 - Parque São Jorge

Florianópolis - SC - 88.034-495

Endereço Eletrônico: alcyane.marinho@hotmail.com 